\title{
Que língua é essa? Crenças, atitudes e identidade na fala do aprendiz brasileiro de inglês
}

\section{What language is that? Beliefs, attitudes and identity in the speech of the Brazilian English Learner}

Letícia Telles da Cruz ${ }^{1}$

Resumo: Esse artigo se propõe a fomentar discussões a respeito da formação da identidade de aprendizes brasileiros de língua inglesa, tomando por base os estudos sobre diversidade linguística, letramento, crenças e formação docente, através do diálogo entre diferentes áreas que estudam a linguagem, como a Linguística Aplicada (LA) e a Linguística Teórica (LT). Para o desenvolvimento das discussões, dados da pesquisa de doutorado realizada pela autora e relatos de estudantes de língua inglesa, gerados em documentos oficiais previstos no Regimento da UNEB, à época da conclusão da graduação, serão revisitados por se constituírem informações relevantes para o objetivo deste artigo.

Palavras-chave: Diversidade linguística; Língua; Identidade; Cultura.

Abstract: This article aims to foment discussions about the formation of the identity of Brazilian English learners, based on studies on linguistic diversity, literacy, beliefs and teacher education, through dialogue between different areas that study language, such as Applied Linguistics (LA) and Theoretical Linguistics (LT). For the development of the discussions, data from the doctoral research conducted by the author and reports of students of English, generated in official documents regulated in the UNEB's Regiment, at the time of graduation, will be revisited because of the relevant information they represent to the objective of this article.

Key-words: Linguistic diversity; Language; Identity; Culture

\section{Construção da identidade do aprendiz brasileiro de inglês}

Inicio esse texto a partir da fala de um aluno do Curso de Letras/Língua Inglesa, do Campus XIV da UNEB, no seu trabalho de conclusão de curso, em 2018.1, quando ele faz a seguinte reflexão:

Retomando a minha contínua aprendizagem de LI, me intrigava quando as pessoas perguntavam: qual inglês você fala? Americano ou Britânico? Eu não me encaixava nas opções citadas e me questionava se todos os americanos ou britânicos falavam da

\footnotetext{
${ }^{1}$ Professora Assistente da Universidade do Estado da Bahia (UNEB), Campus XIV, Conceição do Coité. Email: leticiatlls@gmail.com
} 
mesma maneira. Será possível afirmar que todas as pessoas de determinada nação utilizam a sua língua nativa da mesma forma? E por que eu, brasileiro, devo falar inglês através de um padrão de fala que não me pertence? (RAMOS, 2018, p. 22).

A fala desse aluno motiva discussões sobre língua, cultura e identidade, além de demonstrar claramente a consciência e a atitude de alguém que já se situa social, cultural e politicamente no mundo. A compreensão de cultura e de identidade passa, portanto, a ser prioritária, como aponta Mota (2004, p. 42). Dentro da perspectiva antropológica, a autora define cultura como a incorporação de distintos modos de vida, valores e significados compartilhados por diferentes grupos em determinados períodos históricos. Quanto ao conceito de identidade, ela ressalta os valores de pertencimento e interação social, e em função disso, como vivemos uma variedade de identidades potencialmente contraditórias.

Da mesma forma, Mendes (2012) também enfatiza a necessidade dessa compreensão, salientando que, dentro da concepção global de ser humano, é realmente preciso discutir a concepção de identidade e, por sua vez, a concepção de linguagem, a partir da compreensão de língua como ação entre sujeitos situados social, histórica e culturalmente. Esse deve ser o ponto de partida para se falar sobre o ensino de línguas nos dias atuais e, em especial, sobre o ensino de línguas estrangeiras.

Questiona-se, portanto, na contemporaneidade, a identidade do falante nativo, a sua autoridade, bem como a legitimidade de uma única norma em tempos de grandes migrações e encontros interculturais, além do aumento das diferenças linguísticas e pragmáticas entre falantes de uma mesma língua. Segundo Rajagopalan (2009), os nativos também têm o seu lugar no World English, só que esse lugar não é de privilégio como "donos" ou "falantes autênticos" de uma língua. Eles também terão de se adaptar à nova realidade e por que não aprender novas formas de falar e ouvir? O que alguns estudiosos propõem, então, a exemplo de Byram e Zarate (1994 apud KRAMSCH, 1998) é a mudança da norma do falante nativo para o modelo do falante intercultural. Ou seja, aprendizes de uma língua estrangeira, ao invés de tentarem se aproximar das normas do falante nativo, deveriam aprender como se tornar falantes interculturais.

Tomando como exemplo a língua inglesa, sabemos que a sua expansão como língua internacional para pesquisa, negócios e indústria tem dissociado o falante nativo de inglês da sua localidade geográfica tradicional. $O$ inglês se tornou a língua franca entre pessoas que não falam as mesmas línguas maternas, a fim de suprir suas necessidades e propósitos. Além dessa variação geográfica entre falantes não-nativos, testemunhamos um aumento na diversificação da língua em uso, entre falantes nativos também, o que vai de encontro à afirmação de Davis (1994 apud KRAMSCH, 1998) de que o inglês padrão deveria ser o único modelo usado por falantes não-nativos. Ocorre que, agora, "native varieties of English now include the English spoken and written in Singapore and New Delhi, Nigeria and South Africa, where syntax and vocabulary can sometimes vary considerably from so-called standard English"2. (KRAMSCH, 1998, p. 24).

Assim, estruturas padrão (Language usage - a linguistic concept) precisam ser diferenciadas do uso autêntico da língua (Language use - a social concept). Com base nisso, a noção de único falante nativo, única língua, única cultura passa a ser uma falácia.

Como essas discussões têm sido tratadas nas escolas e nos cursos de formação de professor? Se queremos contribuir para a formação de professores críticos e reflexivos, devemos estar atentos às nossas

\footnotetext{
${ }^{2}$ As variações nativas do inglês incluem o inglês falado e escrito em Singapura e Nova Delhi, Nigéria e África do Sul, onde a sintaxe e o vocabulário podem, às vezes, variar consideravelmente do chamado inglês padrão. (KRAMSCH, 1998, p. 24, tradução nossa).
} 
atitudes e crenças em relação à língua que ensinamos e como ensinamos. Ao questionarmos o que a escola, considerada a mais importante agência de letramento, tem oferecido aos aprendizes, se as suas orientações são congruentes às orientações de outras agências de letramento, como a família, a igreja, a comunidade, adentramos em discussões que têm sido implementadas em diferentes áreas, todas igualmente envolvidas com estudos da linguagem.

Recorro, mais uma vez, às reflexões feitas por Ramos (2018), no seu trabalho de conclusão de curso, quando analisa a sua construção identitária, através dos diferentes papéis que passa a experimentar, com a inserção da prática docente na sua vida profissional em formação, àquela época:

\begin{abstract}
Devo aqui mencionar que nessa pesquisa minha visão como pesquisador foi, a todo momento, influenciada pelo processo de conversão do Luís Miguel aluno ao Luís Miguel professor de LI e da frequente troca de posições que tenho em sala de aula. Como aluno de LI, sempre me interessou a relevante presença de inglês no globo e a importância de aprendê-la no meu contexto. No entanto, me deparei com professores que desconsideravam a questão global - e franca - da língua inglesa e pautavam o ensino na cultura e nos padrões anglófonos, reduzindo a presença da LI no mundo em apenas países nativos. (RAMOS, 2018, p. 20).
\end{abstract}

Via de regra, o que se percebe, em alguns ambientes formais de ensino, são práticas de letramento completamente distanciadas do contexto do aprendiz, das suas comunidades de fala. A escola, ao estabelecer as normas linguísticas aceitas e praticadas pela sociedade considerada "culta" e "letrada", se fechou para outros tipos de letramento e, o que é pior, deixou de considerar o ser social representado por cada aluno, alguém, ao mesmo tempo, ímpar e plural, que precisa também do auxílio da escola, para se desenvolver criticamente. É preciso considerar que a maioria das pessoas no mundo inteiro pertence a mais de uma única comunidade de fala, pois usa uma linguagem em casa, uma na escola, uma no trabalho etc (KRAMSCH, 1998), aspecto também corroborado por Cardoso (2001), especialista em estudos dialetais. Da mesma forma que os estudos sobre letramento, os estudos dialetais se ocupam de investigações sobre a realização da língua em cada grupo social:

\begin{abstract}
Uma rápida visão da realidade atual das comunidades linguísticas mostra as grandes transformações pelas quais têm passado as relações entre os povos. Do isolamento semitotal, caminha-se para a quebra de limites e fronteiras, movida pelo avanço dos meios de comunicação, pela interligação constante entre os centros de povoamento, pelo deslocamento mais intenso dos habitantes de uma região para outra, pela redefinição da constituição demográfica, pela flutuação da população de cada área, estimulada pelos novos mecanismos de caráter econômico e social. Isso tudo leva a que se tenha, hoje, por um lado, usuários da língua mais sedimentados em suas regiões e, por outro, falantes que não só têm grande mobilidade, mas também convivem com uma massa também móvel. (CARDOSO, 2001, p. 37).
\end{abstract}

Tais estudos têm levado à constatação de que as práticas de linguagem diferem dentro de uma mesma cultura e mesma língua e, com isso, questiona-se o conceito de cultura e língua como algo homogêneo. Esse entendimento, que tem se expandido pelo mundo graças ao trabalho de professores, pesquisadores e teóricos da linguagem, tem sido motivado por uma ampliação e mudança na concepção de língua e cultura. As discussões sobre a heterogeneidade da língua e a diversidade sociocultural e linguística de cada povo dá voz aos silenciados por muito tempo, por conta de uma educação excludente, 
homogênea, baseada em parâmetros externos à nossa cultura, mas considerada apropriada, para a manutenção do que vivemos até os dias de hoje. Nesse sentido, Kramsch (1998) afirma que:

\begin{abstract}
An increasing number of scholars are even questioning the appropriateness of the one native speaker norm in a time of large-scale migrations, cross-national and crosscultural encounters, and increasing linguistic and pragmatic differences among speakers of the same language. (KRAMSCH, 1998, p. 163).
\end{abstract}

Esse questionamento também foi feito por Ramos (2018), em relação à prática docente dos seus professores de língua inglesa na educação básica:

\begin{abstract}
Guiados pelo famoso American way of life, os planos de aula dos meus professores negligenciavam a produção em LI nas outras partes do globo e nos fazia pensar que inglês era propriedade apenas dos Estados Unidos. Essa prática resultava no desestímulo de aprender inglês e desapossava os alunos da língua, o que gerava pensamentos como: não vou para os Estados Unidos, logo, não preciso aprender inglês. Ao trocar de posições em sala de aula, busquei desconstruir esses ideais com os meus alunos e os introduzi ao mundo dos World Englishes de Crystal (2007), num processo de disseminação da realidade global da língua inglesa. (RAMOS, 2018, p.20).
\end{abstract}

A globalização, na medida em que tentou promover uma homogeneização cultural, provocou uma crise de identidade global, local e pessoal, causando movimentos de resistência, de revitalização de culturas silenciadas, de afirmação de elementos multiculturais. Nesse contexto, as línguas consideradas internacionais vão perdendo as características culturais de vinculação às identidades nacionais dos falantes nativos que vão, aos poucos, assumindo uma hibridização cultural, como afirmado por Rajagopalan (2009). Essa "hibridização" linguístico-cultural tem sido objeto de estudo tanto da Linguística Aplicada (LA), como da Linguística Teórica (LT), o que torna esse diálogo cada vez mais próximo e fértil.

Enfim, a linguagem é usada por sujeitos que, juntamente com ela, se modificam, se articulam, transitam, se fazem presentes e vivos no mundo, em virtude da característica de ser social que o humano carrega consigo. A sala de aula é, portanto, uma amostra de um grande contexto. No caso espeć́fico de uma sala de aula de $L E$, o ambiente pode favorecer a construção da própria identidade do aprendiz, a partir do contato com uma língua/cultura estrangeira. Na concepção de Brun (2010), é preciso que o professor de LE tenha em mente que

\begin{abstract}
O aprendiz de língua estrangeira gerencia permanentemente a diversidade no seu processo de aprendizagem e, por conseguinte, revisa princípios, reorganiza seus vínculos socioculturais, reelabora sentimentos acerca de si mesmo e do mundo. Deste modo, o contexto de aprendizagem de línguas estrangeiras pode significar uma verdadeira e inerente (re)construção identitária. (BRUN, 2010, p.77).
\end{abstract}

A concepção de heterogeneidade da língua e da cultura também prevê a heterogeneidade dos saberes em cada comunidade de prática. "Esses saberes e conhecimentos heterogêneos estão presentes

\footnotetext{
${ }_{3}^{3}$ Um número crescente de estudiosos tem questionado a adequação de uma única norma do falante nativo em tempo de grandes migrações, encontros internacionais e interculturais e crescente aumento de diferenças linguísticas e pragmáticas entre falantes da mesma língua. (KRAMSCH, 1998, p. 16, tradução nossa).
} 
nas diversas formas de letramento como práticas socioculturais. Abrir a sala de aula para essas heterogeneidades pode significar transformar o caráter excludente da escola" (BRASIL, 2006, p. 108).

\title{
Influência das crenças no ensino/aprendizagem de inglês
}

As percepções que os sujeitos têm sobre língua influenciam as suas abordagens de aprender e ensinar, porque estão alicerçadas em crenças que podem ter sido formadas desde o ensino básico e se configuram bem estáveis à época em que o estudante chega à universidade (PAJARES, 1992). A maior implicação disso é a perpetuação de uma prática pedagógica desprovida de sentido social, de contexto histórico, de valorização da própria cultura.

Entretanto, Mendes (2008, p. 63) salienta que, para ser culturalmente sensível, "é necessário incentivar os aprendizes a reconhecer a língua em suas especificidades não só formais, mas, sobretudo, culturais e contextuais, e também reconhecer-se nela, como sujeito histórico e encaixado em experiências de ser e agir através da língua".

Nesse sentido, uma aluna do curso de Letras/Inglês do Campus XIV da UNEB, ao finalizar a disciplina de Estágio Supervisionado IV (2018.1), fez a seguinte reflexão em seu Memorial de Formação, trabalho de culminância ao final da realização das quatro modalidades de estágio presentes na grade curricular do curso:

\begin{abstract}
Outra crença que foi desconstruída ao longo de minha formação acadêmica foi a crença de que apenas o aprendiz de Língua Inglesa que reproduz a performance dos falantes nativos, especialmente os americanos e britânicos, era o falante que falava de maneira supostamente correta e pura. Ao ler, escrever, discutir e refletir sobre o status global que a língua inglesa possui atualmente, mais especificamente sobre o fenômeno linguístico tratado por Rajagopalan (2009) como World English, percebi que, como nos mostra o próprio, os nativos também têm o seu lugar no World English, só que esse lugar não é de privilégio como "donos" ou "falantes autênticos" de uma língua. (RIBEIRO, 2018, p.10).
\end{abstract}

A literatura a respeito dos estudos sobre crenças dá mostras de que se trata de um assunto de interesse em diversas áreas do conhecimento, que já vem sendo pesquisado e discutido há um período de tempo. Em Linguística Aplicada, o assunto tem despertado a atenção de vários pesquisadores desde meados dos anos 1980, no exterior, e meados dos anos 1990, aqui no Brasil (BARCELOS, 2007).

As crenças são um dos componentes da competência implícita do professor, desenvolvida ao longo de sua vida de maneira inconsciente e responsável por um ensino intuitivo, sem base teórica e metodológica explícita. Essa competência orienta a práxis do professor, juntamente com outras necessárias para isso. Com base no exposto, Almeida Filho (1993, p.21) salienta que "dada uma abordagem de ensinar apoiada no mínimo por uma competência implícita e uma competência linguísticocomunicativa, e a presença de potenciais aprendizes (alunos) já se pode iniciar o processo de ensino". Contudo, o grande diferencial do profissional de LE apoia-se justamente em um perfil que vai além dessas duas competências, que pode ser atingido através de uma formação continuada e reflexiva.

Existem, pois, boas razões que justificam a tentativa de entender porque as crenças de professores em formação são essenciais para a formação desse profissional. Dentre essas razões, as crenças influenciam a aquisição do conhecimento, a definição e seleção de tarefas, a interpretação do 
conteúdo de um curso e o monitoramento da compreensão. Assim, as pesquisas sobre crenças de professores em formação podem ajudar os professores formadores a determinar o currículo e o programa do curso. (PAJARES, 1992). Além disso, Barcelos (2007) aponta que o conhecimento das crenças facilita a compreensão das ações e do comportamento dos aprendizes de línguas, contribui para a utilização de diferentes abordagens pelo professor, previne possíveis conflitos entre as crenças de professores e alunos e pode esclarecer a divergência entre a teoria e a prática dos professores, e entre as crenças de formadores de professores e professores, ajudando-os a entender suas escolhas e decisões.

Da mesma forma que os professores trazem consigo suas crenças para a sala de aula, os alunos também o fazem. Portanto, esse ambiente se torna propício a encontros e desencontros de crenças que orientam as diferentes culturas de aprender e ensinar (ALMEIDA FILHO, 1993). Um tipo de desencontro é a discrepância entre o dizer e o fazer, entre o discurso e a prática. Esse foi o foco da minha pesquisa de doutorado (CRUZ, 2017)4, cujo título foi Entre o dizer e o fazer: implicações das crenças de professores em formação sobre o ensino de língua inglesa em escolas pública.

O resultado dessa pesquisa mostrou, dentre outras coisas, que a mudança no comportamento não implica mudança cognitiva, nem a mudança cognitiva garante uma mudança de comportamento (BORG, 2003). A investigação das experiências e ações de nove participantes da pesquisa, assim como do contexto de cada unidade escolar e sua influência nas experiências (BARCELOS, 2006a), me permitiu inferir crenças que talvez sejam mais conectadas a outras crenças, conforme classificação de Rokeach (1972) em relação à centralidade das mesmas. Isso implica dizer que, quanto mais central for uma crença, mais resistente à mudança. Em geral, essas crenças são relacionadas à identidade (self), o que explica a dificuldade de ressignificá-las, porque fazem parte das histórias e experiências vividas por cada indivíduo.

Os conflitos encontrados durante a regência em Estágio Supervisionado revelaram processos tácitos de construção de uma visão de mundo em que se baseia toda a prática e, por sua vez, ajudaram a evidenciar crenças incongruentes com o discurso afinado com uma bagagem de conhecimento teórico (BORG, 2003).

Para Pajares (1992, p. 323), isso pode ser explicado porque os estudantes são comprometidos com crenças pré-estabelecidas e os esforços para acomodar novas informações e ajustar crenças existentes podem ser quase impossíveis. Isso se fundamenta no princípio da continuidade de Dewey (2009), que diz que, no nosso processo de interação e adaptação ao meio, estabelecemos conexões entre experiências passadas e futuras, e essas conexões estão na base da formação de crenças.

Entretanto, não há dúvida de que os fatores contextuais observados e alegados por eles ao final das observações possam ter afetado a relação crenças/ação, como nos dizem Barcelos (2006b, 2007a), Borg (2003) e Pajares (1992), levando-os a práticas já criticadas por eles mesmos. Tal alegação, por sua vez, pode também ser uma tentativa de desviar-se do reconhecimento de crenças que são bastante centrais.

Em outras palavras, isso quer dizer que nem sempre professores de língua estrangeira em formação, envolvidos em discussões e reflexões sobre diversidade linguística, falantes interculturais, língua, cultura e identidade, abordagem de ensino e aprendizagem de línguas, conseguem, na prática, ressignificar concepções anglófonas da língua, descontextualizadas da realidade do aluno e centradas na estrutura da língua exclusivamente, a destituindo de todo seu valor social, cultural e político. Uma das

\footnotetext{
${ }^{4}$ Pesquisa de Doutorado realizada no Programa de Língua e Cultura da UFBA, sob a orientação da Profa. Dra. Edleise Mendes.
} 
explicações para isso pode ser dada pelos estudos sobre crenças e ensino de língua, foco das minhas pesquisas na área de formação de professor.

Contudo, práticas reflexivas, certamente, irão contribuir na formação desse profissional, como evidenciado nos relatos dos alunos aqui citados e, consequentemente, devem ser estimuladas pelos professores. Para Ribeiro (2018), por exemplo, o conhecimento teórico adquirido durante a graduação a ajudou a rever a maneira como ela percebia o usuário da língua inglesa.

Passei então a compreender que a partir do momento em que a Língua Inglesa adquire status global, esta não pertence mais a um país ou a uma cultura especificamente, mas a todos que dela se utiliza, em consonância com o que pensa Rajagopalan (2009). Entendi que seria necessário se refletir sobre as questões relacionadas à identidade dos aprendizes e de adotar práticas pedagógicas voltadas para a interculturalidade. (RIBEIRO, 2018, p.10).

Uma vez ressignificada determinada crença em relação ao ensino de línguas, a mudança na ação fica também evidenciada, segundo indicam as pesquisas já realizadas. Vejamos o que nos diz Ribeiro (2018), na sua experiência durante o estágio de regência no Ensino Fundamental e no Ensino Médio, realizado em 2017.2 e 2018.1 respectivamente, em uma escola pública do município onde a universidade se localiza:

\begin{abstract}
Eu decidi que não criaria muitas expectativas para não me frustrar. No entanto quando iniciei o estágio de regência fui surpreendida. Os alunos de maneira geral apresentavam um comportamento mais hostil do que o que eu esperava. Fiquei perplexa e desolada ao mesmo tempo. Tamanha indisciplina e irresponsabilidade das turmas em que realizei os estágios III e IV eu nunca tinha visto em seis anos trabalhando como professora. Constatei que o comportamento dos alunos se dava de tal forma por que assim como eu, logo quando iniciei a licenciatura, eles também possuíam muitas crenças sobre o significado de aprender inglês. Aproveitei então a oportunidade para fazê-los refletir sobre o caráter educativo do ensino de Língua inglesa, pois eles apenas relacionavam as vantagens de saber inglês a seu uso prático como viagens ao exterior ou obtenção de emprego. (CONFESSOR, 2018, p. 11).
\end{abstract}

O caráter educativo do ensino de LE está justamente na possibilidade que o aprendiz tem em conhecer a diversidade do mundo e as possibilidades de ser diferente, culturalmente e identitariamente, se situando no seu contexto local e no contexto global (JORGE, 2009).

É possível que, trilhando nessa direção, os aprendizes entendam o sentido e o valor de transitar através das línguas e variedades linguísticas, e não de se deslocar em busca de determinada língua ou variedade que seja mais "valorizada" do que aquela que ele domine. É nesse aspecto que reside a característica de um usuário competente da língua, que não é aquele que usa a língua de acordo com as normas acadêmicas e de etiqueta estabelecidas por um grupo social, mas é aquele que consegue selecionar, com precisão e adequação, as formas que devem ser usadas em determinado contexto social. Essa forma de competência é precisamente a do falante intercultural, que transita entre várias línguas ou variedades linguísticas:

Aprender uma língua nessa perspectiva é aprender a significar nessa nova língua e isso implica entrar em relações com outros numa busca de experiências profundas, válidas, pessoalmente relevantes, capacitadoras de novas compreensões e mobilizadora para ações subsequentes. Aprender LE assim é crescer numa matriz de relações interativas 
na língua-alvo que gradualmente se desestrangeiriza para quem a aprende. (ALMEIDA FILHO, 1993, p. 15).

É nessa direção que o ensino de línguas, em especial o de língua estrangeira, aponta na contemporaneidade, e para isso é imprescindível uma formação do profissional de línguas que seja alicerçada no desenvolvimento de competências necessárias ao seu desenvolvimento humano e profissional, de forma que o torne capaz de lidar com a diversidade cultural, étnica, social, linguística, na qual estamos todos inseridos. O primeiro passo é estar aberto aos diálogos possíveis entre as diferentes áreas de estudo, para que possa compreender o local em que se encontra, a partir de outras experiências e pontos de vista.

\title{
Algumas reflexões para finalizar
}

A partir das discussões aqui desenvolvidas, precisamos ter em mente que, na perspectiva intercultural, aprender uma língua estrangeira implica entrar em relações com os outros, numa busca de experiências relevantes para novas compreensões e ações. Essas relações permitirão a construção da identidade de um usuário de inglês situado localmente e globalmente, capaz de se perceber e se conhecer através da língua-cultura do outro.

Na opinião de Ramos (2018), a partir dessa perspectiva,

\begin{abstract}
Apresenta-se uma possibilidade mais acolhedora de ensino de LI, uma vez que os alunos se sentem proprietários da língua e sujeitos que a moldam de acordo com suas características identitárias que advêm da sua cultura e experiências de vida. Portanto, muitos conceitos - como a questão da pronúncia ou sotaque, por exemplo - devem ser reavaliados e desconstruídos, caso necessário, tendo em vista transmitir as questões francas da língua e semear a aceitação das características individuais de cada falante, posto que elas representam e significam a identidade singular de cada falante. (RAMOS, 2018, p. 19)
\end{abstract}

Dessa forma, a prática da reflexão deve ser sempre empreendida nos espaços educacionais formais, para colaborar com o desenvolvimento de atitudes e hábitos mentais que favoreçam o questionamento e exame crítico de todos os aspectos relacionados à linguagem como, por exemplo, ajudar na compreensão de que a postura native-like de uso da língua, baseada em uma preocupação em seguir uma determinada norma linguística, considerada como padrão, limita o aprendiz brasileiro de língua estrangeira ao conhecimento de mundo e de si mesmo.

Tais momentos de reflexão também poderão favorecer a evidencia de crenças, que podem nortear as atitudes de professores e de alunos em relação ao ensino/aprendizagem de línguas, em especial de uma língua estrangeira.

O desenvolvimento do pensamento crítico-reflexivo de alunos de língua inglesa, especialmente daqueles que se tornarão futuros professores desse idioma, através da conscientização do nosso papel local e global, bem como das nossas crenças em relação ao ensino/aprendizagem de línguas, poderá contribuir para que este ensino, em geral, se torne relevante. Só assim, poderemos nos perceber membros de comunidades discursivas, com propósitos comunicativos individuais e sociais, capazes de nos 
expressar por meio de uma variedade de gêneros textuais que representam a linguagem em uso. Esse é o papel da educação pelo empoderamento (FREIRE, 1987).

\section{Referências}

ALMEIDA FILHO, J. C. P. de. Dimensões comunicativas no ensino de línguas. Campinas: Pontes, 1993. BARCELOS, A.M.F. Researching beliefs about SLA: A Critical Review. In: KALAJA, P.; BARCELOS, A.M.F. (Org.). Beliefs about second language acquisitions: new research approaches. USA: Springer, 2006a. p. 07 - 33. - Cognição de Professores e alunos: tendências recentes na pesquisa de crenças sobre ensino e aprendizagem de língua. In: BARCELOS, A. M. F.; ABRAHÃO, M. H. V. (Orgs.). Crenças e Ensino de Línguas foco no professor, no aluno e na formação de professores. Campinas: Pontes, 2006b. p. 15 - 42. . Reflexões acerca da mudança de crenças sobre ensino e aprendizagem de línguas. Revista Brasileira de Linguística Aplicada, Universidade Federal de Viçosa, v.7, n.2, p. 109 - 138. 2007. . Crenças sobre ensino e aprendizagem de línguas: Reflexões de uma década de pesquisa no Brasil. In: ALVAREZ, M. L. O.; SILVA, K. A. da (Org). Linguística Aplicada Múltiplos Olhares. Brasília: UNB; Campinas: Pontes, 2007a. p. 27 - 69.

BORG, S. Teacher cognition in language teaching: a review of research on what teachers think, know, believe and do. Language Teacher, v. 36, p. 81- 109, 2003.

BRASIL. Orientações Curriculares para o Ensino Médio. Linguagens, códigos e suas tecnologias. Brasília: MEC / SEF, V.1, 2006.2 Disponível em: $<$ http://portal.mec.gov.br/index.php?option=com_content\&view=article\&id=13558:politicas-de-ensinomedio\&catid=195:seb-educacao-basica $>$. Acesso em 04 jan. 2012.

BRUN, M. (Re) Construção identitária no contexto da aprendizagem de línguas estrangeiras. In: MOTA, K.; SCHEYERL,D. (Org.). Recortes Interculturais na sala de aula de línguas estrangeiras. Salvador: EDUFBA, 2010, p. $75-106$.

CARDOSO, S. A. M. Dialectologia: trilhas seguidas, caminhos a perseguir. D.E.L.T.A., 17: Especial, p. 25 - 44. 2001.

CRUZ, L. T. Entre o dizer e o fazer: implicações das crenças de professores em formação sobre o ensino de LI em escolas públicas. Tese (Doutorado em Língua e Cultura), Universidade Federal da Bahia, 2017.

DEWEY, J. How we think. U.S.A: BN Publishing, 2009.

FREIRE, P. Pedagogia do oprimido. 17. ed. Rio de Janeiro: Paz e Terra,1987.

JORGE, M. L. S. Preconceito contra o ensino de língua estrangeira na rede pública. In: LIMA, Diógenes Cândido (org.). Ensino e Aprendizagem de Língua Inglesa: conversa com especialistas. São Paulo: Parábola Editorial, 2009.

KRAMSCH, C. The privilege of the intercultural speaker. In: BYRAM, M; FLEMING, M. Language learning in intercultural perspective. Cambridge, UK: Cambridge University Press, 1998. p. 16 - 31.

MENDES, E. Língua, cultura e formação de professores: por uma abordagem de ensino intercultural. In: MENDES, E.; CASTRO, M.L.S. (Org.). Saberes em português: ensino e formação docente. Campinas, SP: Pontes, 2008. p. $57-77$.

O conceito de língua em perspectiva histórica: reflexos no ensino e na formação de professores de português. In: LOBO, Tânia et ali. Linguistica histórica, histórias das línguas e outras histórias. Salvador-BA: EDUFBA, 2012. p.667 - 678.

MOTA, K. Incluindo as diferenças, resgatando o coletivo - novas perspectivas multiculturais no ensino de línguas estrangeiras. In: MOTA, K.; SCHEYERL, D. (Orgs.). Recortes interculturais na sala de aula de línguas estrangeiras. Salvador: EDUFBA, 2004, p. 35 - 50.

PAJARES, M. F. Teachers' beliefs and educational research: cleaning up a messy construct. Review of Educational Research, v. 62, n. 3, p. 307 - 332. Fall 1992. Disponível em http://www.jstor.org/discover/10.2307/1170741 ?uid=3737664\&uid=2129\&uid=2\&uid=70\&uid=4\&sid=21101990 468737. Acesso em: 13 mar 2012.

RAMOS, L. M. G. Borderless English: Reflexões sobre o papel do professor de Língua Inglesa em Tempos de Língua Franca. Trabalho de Conclusão de Curso. Universidade do Estado da Bahia, Campus XIV, 2018.

RAJAGOPALAN, K. Linguística Aplicada: perspectivas para uma pedagogia crítica. In: crítica: Linguagem, identidade e a questão ética. São Paulo: Parábola Editorial, 2003. p. $105-114$. RIBEIRO, A. C. C. A certeza do caminho. Memorial de Formação. Estágio Supervisionado IV. Universidade do Estado da Bahia, Campus XIV, 2018.

ROKEACH, M. Beliefs, attitude and values. London: Jossey-Bass Inc. Publishers, 1972. 